\title{
Left ventricular non-compaction cardiomyopathy with coronary artery anomaly complicated by ventricular tachycardia
}

\author{
Gustav Mattsson ${ }^{1 *}$ (D), Abdullah Baroudi ${ }^{2}$, Hoshmand Tawfiq ${ }^{1}$ and Peter Magnusson ${ }^{1,3}$
}

\begin{abstract}
Background: Non-compaction cardiomyopathy (NCCM) is characterized by prominent trabeculations, deep intertrabecular recesses, and a thick non-compacted endocardial myocardium. Prevalence in the general population remains unclear, but echocardiography series report $0.05 \%$. During fetal development muscle fibers and trabeculae should compact into a solid myocardium and when this fails, NCCM occurs. The condition is genetic, even though acquired forms have been described. Worsening myocardial dysfunction may lead to heart failure and/or arrhythmias.
\end{abstract}

Case presentation: A 52-year-old man presented with heart failure. The diagnosis of NCCM was confirmed after echocardiography and cardiac magnetic resonance tomography. Interestingly, the angiogram revealed a coronary anomaly, in which the circumflex artery rose aberrantly from the right coronary artery. Due to left ventricular ejection fraction being less than 35\% despite optimal pharmacological therapy, an implantable cardioverter defibrillator (ICD) was implanted and four years later a ventricular tachycardia was terminated by antitachycardia pacing.

Conclusion: We describe a case of NCCM with a concomitant coronary anomaly, in which systolic myocardial dysfunction developed. The ICD subsequently terminated a life-threatening ventricular arrhythmia, which supports risk stratification based on low ejection fraction and possibly coronary anomaly.

Keywords: Cardiac imaging, Cardiac magnetic resonance, Cardiomyopathy, Coronary artery anomaly, Echocardiography, Heart failure, implantable cardioverter defibrillator, Non-compaction cardiomyopathy, Sudden cardiac death, Ventricular tachycardia

\section{Background}

Non-compaction cardiomyopathy (NCCM) was first described in 1984 as a clinical entity and is a heterogeneous cardiomyopathy that can occur at any age $[1,2]$. Congenital NCCM is caused by a defect in compaction of muscle fibers during fetal development, resulting in a spongiform myocardium. It appears that NCCM can also be acquired, for example due to athlete's heart [3]. In a large hospital cohort the prevalence was $0.05 \%$, and there seems to be

\footnotetext{
* Correspondence: gustav.mattsson@regiongavleborg.se

${ }^{1}$ Centre for Research and Development, Uppsala University/Region

Gävleborg, SE-801 87 Gävle, Sweden

Full list of author information is available at the end of the article
}

an increased awareness among clinicians about NCCM [4]. Echocardiographic diagnosis is based on four criteria (Jenni criteria): absence of other cardiac abnormalities, end-systolic ratio between non-compacted endocardial myocardium and compacted epicardial myocardium of $>2$, localization of hyper-trabeculation to the apex/mid-inferior/mid-lateral areas, and color doppler showing blood flow from the ventricle into deep intertrabecular recesses without communication with coronary vessels [5]. Some patients with NCCM are asymptomatic, others develop heart failure with reduced systolic ejection fracture (EF). NCCM may increase the risk of ventricular tachycardia, and the risk of thromboembolism, likely due to reduced 


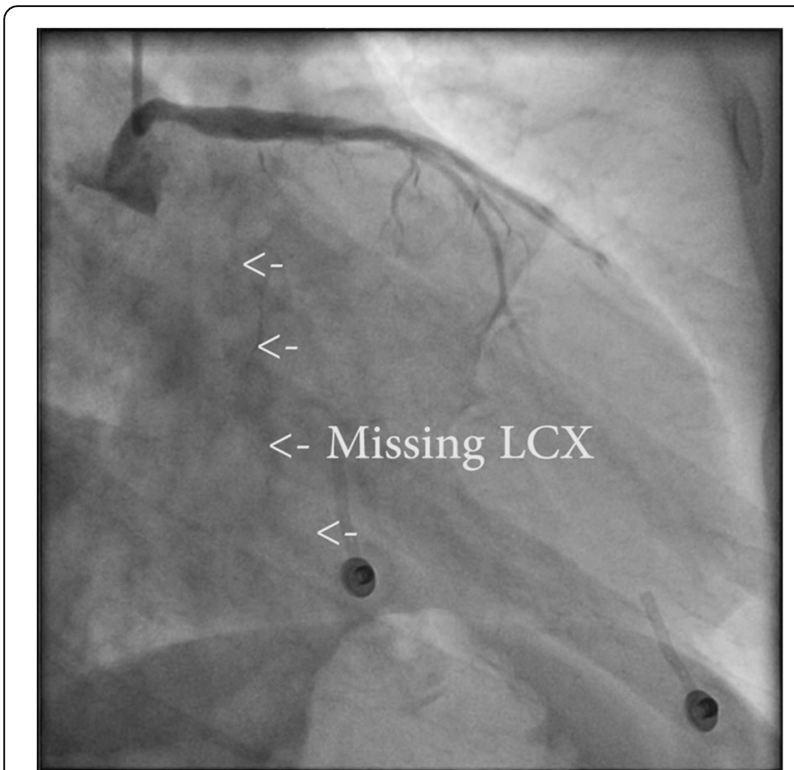

Fig. 1 Coronary angiogram, left anterior oblique view with caudal angulation showing left coronary artery and left anterior descending artery, without any circumflex artery (missing LCX)

blood flow in the intertrabecular recesses [6]. NCCM exhibits familial clustering, with point prevalence of phenotype being 30\% in first-degree relatives [7]. Genes encoding sarcomeric and cytoskeletal proteins have been implicated in NCCM, as well as genes previously linked to such disorders as hypertrophic cardiomyopathy, mitochondrial diseases, Barth syndrome, and myotonic dystrophy [8].

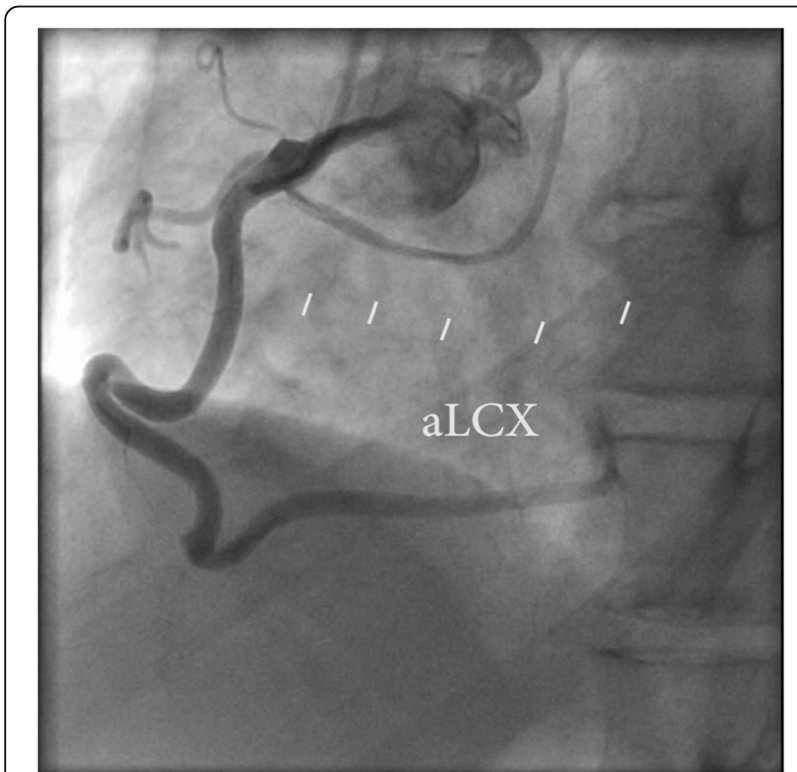

Fig. 2 Coronary angiogram, right anterior oblique view with cranial angulation showing right coronary artery giving rise to a thin aberrant circumflex artery (aLCX)

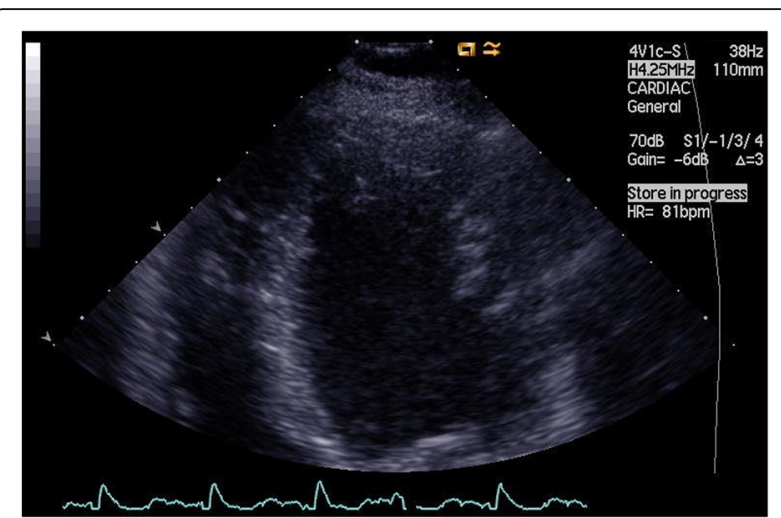

Fig. 3 Transthoracic echocardiogram, end-diastole, apical four-chamber view showing prominent trabeculations in the left ventricular wall

\section{Case presentation}

A 52-year-old man presented with dyspnea, chest discomfort, and palpitations upon exertion. His parents had confirmed ischemic heart disease. ECG at rest showed sinus rhythm, premature ventricular complexes and poor R-wave progression in precordial leads $V_{1}$ to $\mathrm{V}_{4}$. The first echocardiography revealed general hypokinesia, predominantly in the anterior wall, thin walls without dilatation, EF around 35\%, and high and pointy E-waves, indicative of a restrictive pattern. He reached $200 \mathrm{~W}$ on cycle ergometer exercise testing, but with frequent premature ventricular complexes. Angiography (Figs. 1 and 2.) showed no signs of coronary artery disease. Surprisingly, a coronary anomaly was revealed, in that the circumflex coronary artery (LCX) originated from the right coronary artery (RCA). At this point, cardiac magnetic resonance (CMR) imaging did not provide any further diagnostic clues. The situation was complicated by atrial fibrillation that was electrically converted but recurred at two-year follow-up. Another echocardiogram (Figs. 3, 4 and 5) was performed that for the first time raised suspicion of NCCM with

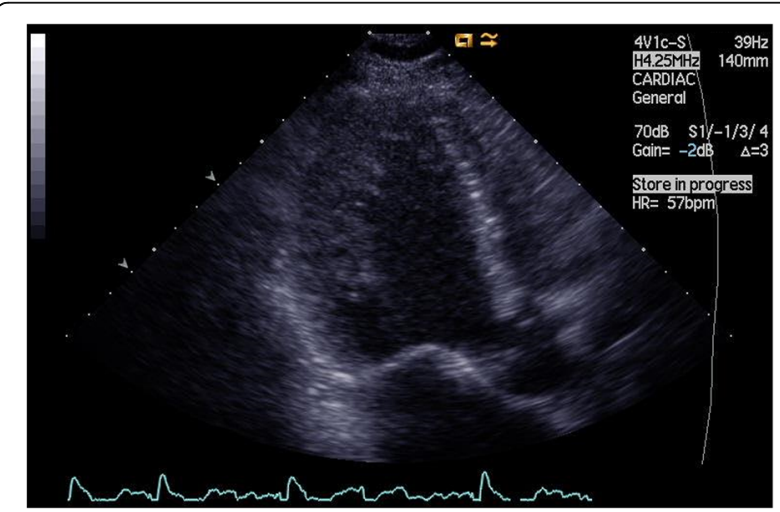

Fig. 4 Transthoracic echocardiogram, systole, apical long-axis view showing a thick non-compacted myocardium in the left ventricular wall 


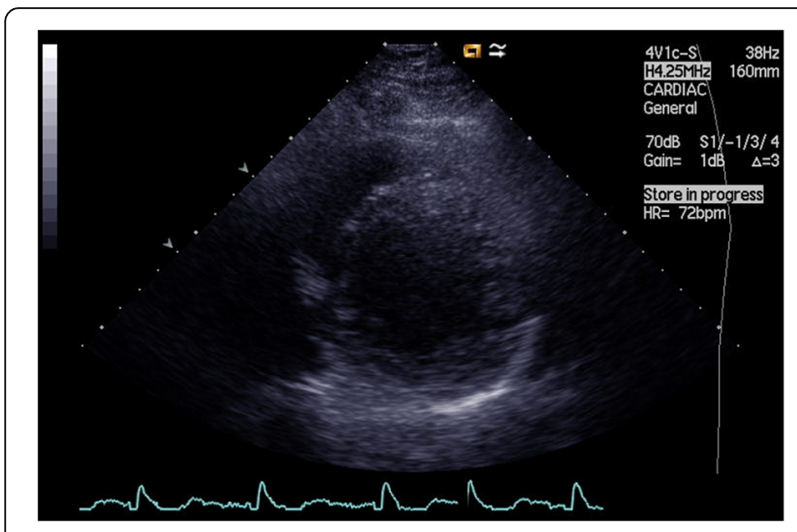

Fig. 5 Transthoracic echocardiogram, end-diastole, parasternal short axis view showing hypertrabeculation of the inferolateral left ventricular wall

EF around 30\%. There were hypokinesia and deep intramyocardial recesses in the left ventricular wall. The ratio of non-compacted to compacted myocardium was 2.4 measured in the apical long-axis view, midinferior, at end-systole.

The patient was referred to a tertiary center for evaluation including right ventricular catheterization and endomyocardial biopsy that did not suggest any alternative diagnoses. Repeated echocardiograms confirmed the diagnosis of NCCM. An implantable cardioverter defibrillator (ICD) with a single lead (QRS < $120 \mathrm{~ms}$ ) was offered to the patient for primary prevention of sudden cardiac death (SCD). Four years later, antitachycardia pacing terminated a life-threatening monomorphic ventricular tachycardia of 200 beats per minute (Fig. 6.). The patient has been followed for another three years and is on beta-blocker, angiotensin receptor blocker, and eplerenone therapy. In that time, he has had no further arrhythmias requiring ICD therapy and is New York Heart Association (NYHA) functional class II. The CARE guidelines were followed in the writing of this report.

\section{Discussion and conclusions}

Clinical presentations of NCCM are heterogeneous and $35 \%$ have no hypertrophy or dilation of the ventricle. NCCM in the absence of arrhythmia seem to have similar survival rates as the general population [6]. Patients with NCCM with arrhythmia, are believed to have worse prognosis than patients with similar arrhythmias alone. Other forms of NCCM include dilated, hypertrophic, and restrictive pattern. NCCM typically affects the left ventricle, but biventricular and isolated right ventricular manifestations do occur [6]. There is no specific therapy for NCCM, but if heart failure is present this should be treated according to guidelines [9]. In our patient, metoprolol, enalapril, and eplerenone were titrated. The classic triad of NCCM consists of thromboembolism together with arrhythmia and heart failure. Anticoagulation is advocated

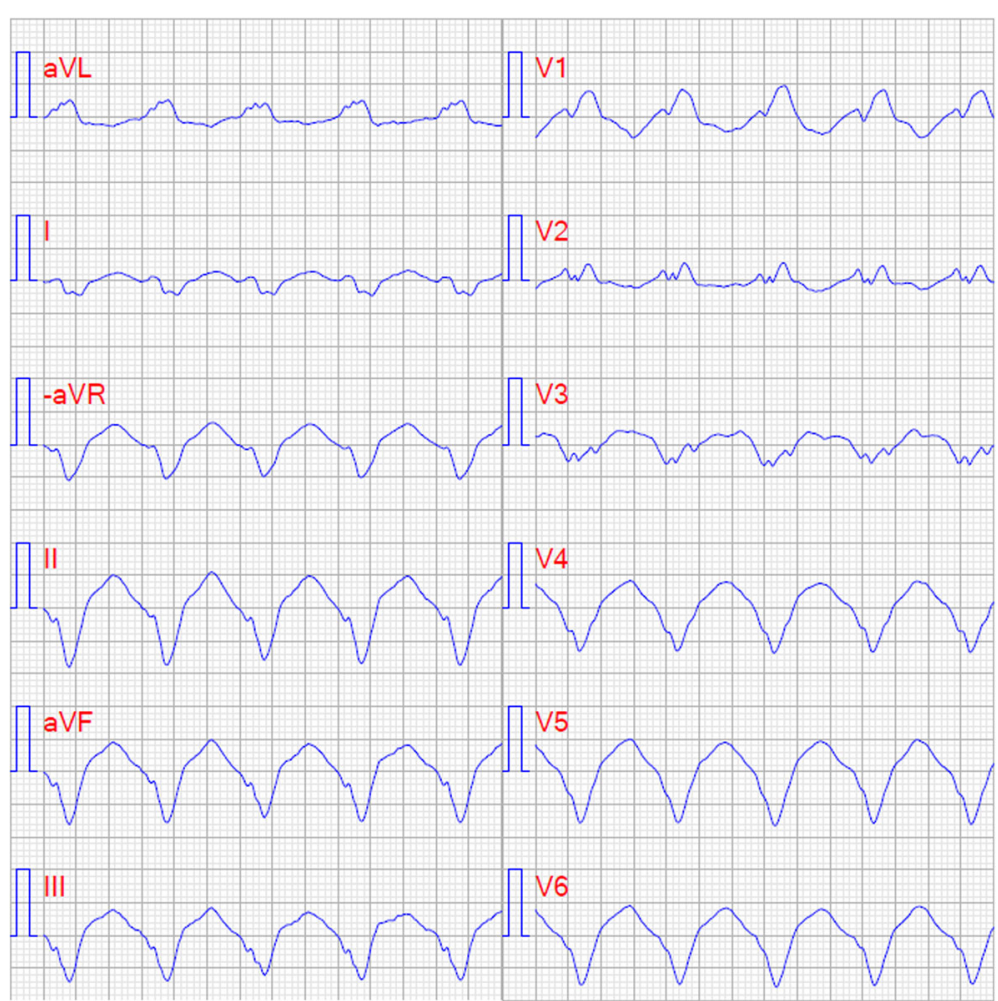

Fig. 6 Electrocardiogram of monomorphic ventricular tachycardia, 200 beats per minute (paper speed $50 \mathrm{~mm} / \mathrm{s}$ ) 
if NCCM is associated with either atrial fibrillation, severe heart failure, confirmed thrombus, or previous thromboembolism [10]. In our patient, anticoagulation with warfarin was initiated due to atrial fibrillation and heart failure.

The Jenni echocardiography criteria are widely used but they can be difficult to validate and there is a lack of consensus about them [5]. CMR can provide additional value with borderline cases or in patients in whom differential diagnoses like hypertrophic cardiomyopathy are difficult to rule out. An end-diastolic ratio between noncompacted and compacted layers of $>2.3$ is considered diagnostic [11]. Late gadolinium enhancement in trabeculae is indicative of fibrosis and correlates with clinical severity [12].

This case report describes concomitant NCCM and aberrant LCX arising from the RCA, which occurs in $0.37 \%$ of angiograms [13]. Other coronary anomalies have previously been described together with NCCM, a single coronary artery of anomalous origin [14], as well as an anomaly including four arteries arising from the RCA with an LCX arising directly from the aorta [15]. How common coronary anomalies are in patients with NCCM is unknown, because the rarity of both conditions makes this difficult to study. Given the common pathogenesis of abnormalities in embryogenesis, an overrepresentation is plausible. The presence of coronary anomalies provides a challenge in risk stratification for SCD. The anomaly present in this case, aberrant LCX from the RCA, is generally not linked to an increased risk of SCD. In cases where the aberrant LCX travels between the aorta and the pulmonary artery, increased SCD has been reported, likely caused by compression or angulation of the artery [13].

The efficacy of ICD treatment in preventing death from arrhythmia is well established [16]. The European Society of Cardiology guidelines regarding SCD state that NCCM without further risk factors is not an indication for ICD. It is suggested to use the same criteria for risk stratification in NCCM as in non-ischemic, dilated cardiomyopathy [17]. ICDs should be offered to survivors of ventricular arrhythmias regardless of the underlying cardiac etiology. ICD should be offered as primary prophylaxis to NCCM patients with EF $\leq 35 \%$ and NYHA functional class II-III despite at least three months of optimal pharmacological therapy, and an otherwise reasonable life expectancy. Despite the limitations of EF estimation in individual patients, it still provides the best discriminator for risk stratification in most cardiomyopathy types $[17,18]$. We believe that the current approach of risk stratification is advisable until more specific data of NCCM are available. The ICD in our patient terminated a life-threatening arrhythmia.
This should encourage careful risk stratification in NCCM based on generalized knowledge from other cardiomyopathies.

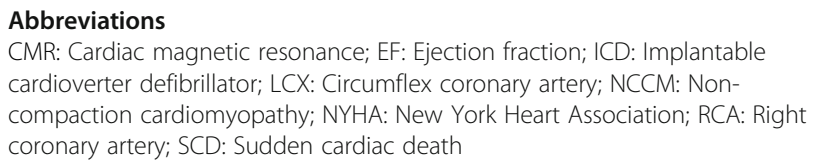

\section{Acknowledgements}

Images of the coronary angiogram were provided by Lasse Hellsten, and echocardiography exams by Ann-Charlotte Larsson. Jo Ann LeQuang of LeQ Medical reviewed the manuscript for American English use.

Funding

There is no funding pertaining to the manuscript.

\section{Availability of data and materials}

All relevant data supporting the conclusions of this article is included within the article.

\section{Authors' contributions}

GM: design, data collection, major writing AB: design, writing HT: patient management, critical revision PM: idea, design, writing, patient and project management. All authors read and approved the final manuscript.

Ethics approval and consent to participate

Not applicable.

\section{Consent for publication}

Written informed consent was obtained from the patient for publication of this case report and any accompanying images. A copy of the written consent is available for review by the editor of this journal.

\section{Competing interests}

The authors declare that they have no competing interests.

\section{Publisher's Note}

Springer Nature remains neutral with regard to jurisdictional claims in published maps and institutional affiliations.

\section{Author details}

${ }^{1}$ Centre for Research and Development, Uppsala University/Region Gävleborg, SE-801 87 Gävle, Sweden. ²Department of Medicine, Kiruna sjukhus, Region Norrbotten, SE-981 28 Kiruna, Sweden. ${ }^{3}$ Cardiology Research Unit, Department of Medicine, Karolinska Institutet, SE-171 76 Stockholm, Sweden.

Received: 22 August 2017 Accepted: 10 October 2017

Published online: 16 October 2017

\section{References}

1. Engberding R, Bender F. Identification of a rare congenital anomaly of the myocardium by two-dimensional echocardiography: persistence of isolated myocardial sinusoids. Am J Cardiol. 1984;53:1733-4.

2. Elliott $P$, Andersson B, Arbustini E, Bilinska Z, Cecchi F, Charron P, et al. Classification of the cardiomyopathies: a position statement from the European Society of Cardiology working group on myocardial and pericardial diseases. Eur Heart J. 2008;29:270-6.

3. Gati S, Chandra N, Bennett RL, Reed M, Kervio G, Panoulas VF, et al. Increased left ventricular trabeculation in highly trained athletes: do we need more stringent criteria for the diagnosis of left ventricular noncompaction in athletes? Heart. 2013;99:401-8.

4. Ritter M, Oechslin E, Sütsch G, Attenhofer C, Schneider J, Jenni R. Isolated noncompaction of the myocardium in adults. Mayo Clin Proc. 1997;72:26-31.

5. Jenni R, Oechslin E, Schneider J, Attenhofer Jost C, Kaufmann PA. Echocardiographic and pathoanatomical characteristics of isolated left ventricular non-compaction: a step towards classification as a distinct cardiomyopathy. Heart. 2001;86:666-71. 
6. Towbin JA, Lorts A, Jefferies JL. Left ventricular non-compaction cardiomyopathy. Lancet. 2015;386:813-25.

7. Bhatia NL, Tajik AJ, Wilansky S, Steidley DE, Mookadam F. Isolated noncompaction of the left ventricular myocardium in adults: a systematic overview. J Card Fail. 2011;17:771-8.

8. Finsterer J. Cardiogenetics, neurogenetics, and pathogenetics of left ventricular hypertrabeculation/noncompaction. Pediatr Cardiol. 2009;30:659-81.

9. Ponikowski P, Voors AA, Anker SD, Bueno H, Cleland JG, Coats AJ, et al. 2016 ESC guidelines for the diagnosis and treatment of acute and chronic heart failure: the task force for the diagnosis and treatment of acute and chronic heart failure of the European Society of Cardiology (ESC) developed with the special contribution of the heart failure association (HFA) of the ESC. Eur Heart J. 2016;37:2129-200.

10. Finsterer J, Stöllberger C, Towbin JA. Left ventricular noncompaction cardiomyopathy: cardiac, neuromuscular, and genetic factors. Nature reviews. Cardiology. 2017;14:224-37.

11. Petersen SE, Selvanayagam JB, Wiesmann F, Robson MD, Francis JM, Anderson $\mathrm{RH}$, et al. Left ventricular non-compaction: insights from cardiovascular magnetic resonance imaging. J Am Coll Cardiol. 2005;5(46):101-5.

12. Dodd JD, Holmvang G, Hoffmann U, Ferencik M, Abbara S, Brady TJ, et al. Quantification of left ventricular noncompaction and trabecular delayed hyperenhancement with cardiac MRI: correlation with clinical severity. Am J Roentgenol. 2007;189:974-80.

13. Villa AD, Sammut E, Nair A, Rajani R, Bonamini R, Chiribiri A. Coronary artery anomalies overview: the normal and the abnormal. World J Radiol. 2016;8:537-55.

14. Park JS, Shin DG, Kim YJ, Hong GR, Kim W, Lee SH, et al. Left ventricular noncompaction with a single coronary artery of anomalous origin. Int J Cardiol. 2007;119:35-7

15. lacovelli F, Pepe P, Contegiacomo G, Alberotanza V, Masi F, Bortone AS, et al. A striking coronary artery pattern in a grown-up congenital heart disease patient. Case Rep Cardiol. 2016;2016:5482578.

16. Goldenberg I, Gillespie J, Moss AJ, Hall WJ, Klein H, McNitt S, et al. Longterm benefit of primary prevention with an implantable cardioverterdefibrillator: an extended 8-year follow-up study of the multicenter automatic defibrillator implantation trial II. Circulation. 2010;122:1265-71.

17. Priori SG, Blomström-Lundqvist C, Mazzanti A, Blom N, Borggrefe M, Camm J, et al. 2015 ESC guidelines for the Management of Patients with ventricular arrhythmias and the prevention of sudden cardiac death: the task force for the management of patients with ventricular arrhythmias and the prevention of sudden cardiac death of the European Society of Cardiology (ESC). Endorsed by: Association for European Paediatric and Congenital Cardiology (AEPC). Eur Heart J. 2015;36:2793-867.

18. Bardy $\mathrm{GH}$, Lee $\mathrm{KL}$, Mark DB, Poole JE, Packer DL, Boineau R, et al. Amiodarone or an implantable cardioverter-defibrillator for congestive heart failure. N Engl J Med. 2005;352:225-37.

\section{Submit your next manuscript to BioMed Central and we will help you at every step:}

- We accept pre-submission inquiries

- Our selector tool helps you to find the most relevant journal

- We provide round the clock customer support

- Convenient online submission

- Thorough peer review

- Inclusion in PubMed and all major indexing services

- Maximum visibility for your research

Submit your manuscript at www.biomedcentral.com/submit

) Biomed Central 